rianic acid, will be found serviceable in cases associated with hysterical symptoms, such as the globus hystericus, and other spasmodic affections.! After a time, chalybeates will be advantageously replaced, for a short period, by vegetable tonics and mineral acids. The most suitable of these, to alternate with the preparations of iron, are, in my opinion, the decoction of cinchona in combination with dilute sulphuric acid,-far more efficacious than sulphate of quinine; the infusion of gentian with this acid, or the hydrochloric; tannin, in doses of half a grain, dissolved in infusion of gentian and combined with nitric acid, a most efficient roborant combination, in this and many other diseases, including phthisis pulmonalis.

These vegetable tonics and mineral acids will likewise be found well adapted to cases of Goître, associated with general debility, independent of anæmia. In such examples, requiring cordial treatment, the tinctures should be employed in preference to infusions; and when a nervine or composer is required, the tincture of hops will prove highly advantageous, either with or without the aromatic spirits of ammonia, as circumstances may indicate.

The regimen most suitable for cases of Goitre is well known, and therefore may be dismissed in a few words. It should embrace a substantial diet, regularity, and exercise in the open air. The place of residence, if infested with the disease, should be changed, if possible, for a locality with a dry soil, open country, and a pure invigorating atmosphere.

Park-street, Grosvenor-square, May 1849.

\title{
CLINICAL OBSERVATIONS.
}

By JOHN ROSE CORMACK, M.D. Edin., F.R.S.E., Fellow of the Royal College of Physicians of Edinburgh, and formerly one of the Physicians of the Royal Infirmary and Fever Hospitals of that City.

No. II.-CASES OF PUERPERAL CONVULSIONS : DEPENDENCE OF PUERPERAL CONVULSIONS ON TOXEMIA : EXPLANATION OF THE MORE COMMON OCCURRENCE OF RENAL CONVULSIONS IN PRIMIPARE.

(Read before the $W$ estminster Medical Society, May 12, 1849.)

Is observations formerly made, on a Case of Scarlatinous Albuminous Nephritis, ${ }^{2}$ it was stated that an albuminous condition of the urine was, per se, no sign of structural renal disease : that it indicated congestion of the kidney, and nothing more. I cited the experiments on rabbits made by Dr. George Robinson of Newcastle, and likewise a series of clinical facts, as amply establishing this important truth; and among other illustrations of toxæmia, caused by the congested kidneys being unable to eliminate excrementitious products from the blood, I mentioned the Convulsions of Pregnant Women.

1 Some Jears apo, when the valerianate of zinc was introduced into prectice, I applied to Mr. Morson for a valerianate of iron. He kindly supplied me with a small quantity dir. solved in spirit; which is still in good preservation.

- Losdon Jovrenat of Medicink, vol. for 1849, p. 451. 
On the present occasion, I embrace the opportunity of pursuing this subject a little farther, and of endeavouring to show that Puerperal Convulsions are-though not always-yet generally the toxicological results of non-elimination of the excrement of the blood; and that in by far the largest number of cases, this non-elimination depends on renal congestion, caused by the pressure of the gravid uterus. When structural renal disease coexists with a gravid uterus, the risk of Puerperal Convulsions seems to amount almost to a certainty; as diseased kidneys are liable to have their functions disturbed by slight causes, and are specially disposed to congestion.

Albuminuria and dropsy are symptoms associated with Renal Puerperal Convulsions : and, independent of pregnancy, they have been proved to be sure signs of retardation of the flow of blood in the emulgent veins. The proofs are twofold. First, ligature of these vessels in the lower animals induces rapid renal congestion and albuminuria; and secondly, the records of Clinical Medicine inform us, that this condition of the urine, and likewise dropsy, are caused by aneurism, enlarged ovary, or any abdominal tumour, producing a similar, even though less perfect, mechanical impediment to the return of blood from the kidney. When we have albuminous urine, we have congestion of the kidney: when we have congestion of the kidney, we have its emunctory office inadequately performed ; and whenever the insufficiency of renal depuration of the blood proceeds beyond a certain point, the blood becomes so poisonous as to act toxicologically on the brain. This, in passing it may be observed, is the explanation of the frequency of convulsions coming on in the course of Bright's diseese. Slight causes may at any time excite such an increase in the congestion as to induce conrulsions, stupor, or sudden death.

Dr. Tyler Smith has handled the subject of Puerperal Convulsions more philosophically than any preceding writer: but he appears to me to attribute them rather too sweepingly to irritation of the extremities of the nerves; and (while he recognizes their influence), to attach too little importance to direct toxæmic impressions on the nervous centres. With reference to the kidney, he remarks: "Irritation of the kidney has been known to excite epilepsy, and most probably it would act as a cause of Puerperal Convulsions. Lamotte and others have recorded cases of this kind. It is an old remark, that oedema of the face and neck forms a frequent premonitory attack; and Dr. Lever has made the interesting and important observation, that albuminuria is present in many instances. These points," continues Dr. Smith, " require farther examination, with special reference to the different modes in which spinal action may be excited." 1

Excluding a case of delirium and convulsions occurring in an abortion during Scarlatina (and which is briefly noticed by Dr. Tyler Smith (p. 326) as having been seen by him, with me), two cases have recently occurred in my practice, or I may say three, because one of the patients had convulsions in two succeeding pregnancies. Both were maried:

I Sxrra (Dr. Tylex) on Parturitiou ; and the Principles and Practice of Obstetrics, p. 306. London: 1849. The reader is also referred to pp. 293-4, where Dr. Smith fully recognizes the influence of toxwmia a centric canse of Convulsions. 
and both were primipare. The case of abortion in Scarlatina is extremely interesting; but being a special one, I must defer its history, and the remarks suggested by it, to some other occasion.

CASE I. On the 27th October 1846, at 11 P.M., I was called to Mrs. S., whom I had been previously engaged to attend. It was her first pregnancy; and she was at the full time. From her diminutive stature, narrow pelvis, and excessive abdominal bulk, I had been looking forward to the labour with some anxiety, and had requested that I might be sent for, as soon as the pains of parturition set in. On my arrival, I found that she had been in labour for two or three hours, and that the pains were severe, and coming on at intervals. On examining digitally the state of the os uteri, I found that there was no dilatation whatever. For four or five hours, the pains continued to recur at short intervals : she suffered extreme agony; and the abdominal muscles were called into energetic action: still, lahour hardly advanced, and at 5 A.M. the os was not more dilated than to admit the point of the fore-finger. Till then, she had had no cerebral symptoms; but about that time, I was alarmed at observing incoherence in her conversation, and stertorous breathing during the short and disturbed slumbers, which at this period occupied the intervals between the pains. Between 5 and 6 A.M. a cathartic draught acted, which had been administered on my discovering, when I arrived, that the bowels had not been moved for two or three days. Immediately after the operation of the medicine, the countenance greatly improved. Dilatation of the os also seemed advancing. As the strength and spirits were good, I had resolved to wait a little longer without interfering: but events occurred, which prevented me from remaining entirely passive. The mouth became contorted; and she had, within half an hour, a succession of slight epileptic-like seizures, each succeeding attack increasing in severity. The full pulse, swollen countenance, and turgid cervical veins, coupled with the rigid condition of the os uteri, convinced me that the safety of the patient required immediate venesection. In these circumstances, about 8 A.M. I bled her from the arm; and administered a dose of tartar emetic. The bleeding was twice repeated, from twelve to fifteen ounces being taken on each occasion, and the nauseating effect of the antimony was kept up. The intentions of this treatment were threefold: first, to relieve the vascular system; second, to promote dilatation of the os uteri; and third, to moderate the expulsive action of the uterus and abdominal muscles, till such time as the passage should be somewhat relaxed. The convulsions slightly returned during each recurrence of the pains, but with one or two exceptions the spasms were chiefly confined (so far as I could observe), to the muscles of the abdomen and neck. The pulse upon one occasion, immediately before one of the first most severe seizures, was so low as 50 ; but when the convulsions had almost ceased, the pulse rose to 80 , which it numbered at noon. At this time, the tartar emetic had been suspended for an hour, and the membranes could be easily felt protruding from the womb : they burst with a discharge of liquor amnii, of unusual abundance. After this, the pain caused by the pressure of the hand seemed agonizing, and the nervous excitement of the patient was great. A grain of solid opium was administered. From this time, everything went on well : and at 4 P.M. (after 
a labour of twenty hours) a living child was born. The head was strangely elongated : but in a few days there was nothing unusual to be seen in its shape. The placenta was removed by the hand without difficulty about 5 P.M., and another opiate administered. The patient had a long and refreshing sleep; and, till this day, has had no return of convulsions. She went on favourably for three days, when she was seized with phlegmasia dolens, which made her recovery tedious, though it was ultimately complete. This patient was odematous in the face and hands and ankles, during the latter months of pregnancy : but unfortunately, the urine was not examined before, during, or after labour.

Case Il. Mrs. H., a married woman, aged 18, muscular, plethoric, of rather short stature, with abundant black hair, and reported to hare been always very ruddy when in her usual health. At 9 A.M. on the 5th August 1848, I was hurriedly sent for to see this patient, who, $I$ was informed, was in the commencement of the seventh month of her first pregnancy. I found her in a state of insensibility, and emerging from an attack of convulsions, which, from the account I received, must have been tolerably severe. The os uteri was not dilated to any extent. She had been seen by. my assistant two hours previously, at which time she had had no convulsive attack, but complained of pain in the head, noise in the ears, and dimness of vision. The members of her family had observed, on the preceding evening, a wildness in her expressions, and something approaching to delirium. Cold to the head, and a brisk cathartic, had been ordered before I saw the patient: but only the first part of the prescription had been attended to. As the howels were reported by those in attendance to be confined, as the draught had not operated, and as the jaws were so firmly clenched as not to admit of anything being got into the mouth, I directed a cathartic enema to be administered immediately, ordered the feet, which were very cold, to be wrapped up in moist hot flannels, and an evaporating lotion for the head, which was very hot, to be diligently used till I returned. The limbs, chest, and abdomen, were of a natural temperature. At this my first visit, the pulse was full, very slow, (not above 50, I think, and occasionally intermitting: the tongue was dry, and thickly coated with a yellowish fur. During my visit, consciousness returned, though her ideas remained confused, and many of her answers to questions were incoherent. She complained of a soreness of the tongue, gums, and inside of the mouth. Her chief complaint, however, was of backache, and pain in the abdomen, which latter was increased on pressure. She complained of intense headache, and much mental bewilderment. After the convulsions had entirely subsided, I observed that the superficial veins in all parts of the body, but especially those in the head, neck, and arms, still remained very turgid. There seemed to be slight general anasarca: at all events, there was well marked odema under the eyes, at the wrists, and at the ankles. The marriage ring on her finger, from its narrowness, seemed imbedded in the flesh. It was this which first drew my attention to her cedematous condition, which might otherwise, as regarded the countenance, have passed with me for extreme plumpness, as, from not having before seen the patient, I was unacquainted with her natural appearance.

I was obliged to be absent from 10 till 12. On returning, I found 
her in strong convulsions. She lay on her back, in a rigid state, with the head thrown backwards, the face distorted, the mouth foaming, and the breath hissing fitfully through the apertures of the clenched teeth. The muscles of the arms, legs, and abdomen, were in a state of tetanic rigidity, with transient intervals of very partial and slight relaxation. The spasmodic morements of the neck and face were more active and varied. After remaining some time in this state, she struggled violently, sat up, and tore her bed-clothes and dress with her teeth and hands. At this time, or rather just as this active state was abating, the muscles of the abdomen were seen as the painter and the sculptor strive to represent them, when they wish to pourtray extreme athletic tension. On repeating the digital examination, there was still found to be no dilatation of the os uteri. The enema had not been administered, in consequence of the violent resistance of the patient, and the want of tact, or the timidity, of those in attendance. I therefore ordered it to be given immediately; and waited in the house till the bowels had been relieved by it. After a very abundant evacuation of black, hard, and fœetid fæces, the patient became decidedly more natural in appearance: and I left her about 1 P.M. pretty tranquil, almost asleep, and quite free from any convulsive affection. When I returned at 2 P.M. she was asleep; and I was told that she had continued in this state since I had gone away : that at first she had seemed easy, and breathed freely, but that she had gradually become restless, flushed in the face, had shrieked suddenly several times, and had, just before I entered, attempted to get out of bed. Her face was of a deep red, or almost purple colour, her breathing was stertorous, and there was great turgidity of the external vessels of the head and neck. There was slight twitching at the angles of the mouth. I attempted to rouse her by laying my hand on the shoulder, and then gently shaking her: when, immediately-but whether in consequence of, or simply coincident with, this movement of her body, I cannot sayshe became seized with violent convulsions, the paroxysm differing in no respect from the aspect of a severe fit of epilepsy. Everything bad been already prepared for performing venesection; so $I$ at once opened a vein in the arm. The blood flowed in a full and rapid though unsteady stream : and whilst it flowed, the patient was held with the head and shoulders raised by several attendants. The turgidity of the veins of the head and neck soon abated; and the convulsions, though very fright. ful during the whole time of the bleeding, had notably diminished in severity before its conclusion. From the condition of the patient, some of the blood was dispersed over the bed and the apartment; but I think the quantity taken was not less, and perhaps a little more, than twenty fluid ounces, apothecaries' measure. The bleeding seemed greatly to relieve the embarrassed respiration, and to diminish the stupor; but the convulsions, though decidedly less severe, and of a less apoplectic aspect, continued to recur about once every hour till 9 P.M. The first symptom of a coming convulsion was raising her hand to the head, turning up the eyes, and before some of the seizures, in addition to these threatening signs, she shrieked. After the bleeding, I had ordered an antispasmodic mixture, containing opium, valerian, and assafoetida, to be regularly taken at short intervals, hut, as I can testify from the trials which I made mysclf, it was quite impossible, without causing dangerous excitement, 
to make any forcible or even persuasive attempt, to get her to swallow a dose of this or any other medicine. When apparently conscious of what she was doing, she was violent, reckless, and obstinate in her behaviour,-in fact, maniacal. The vein was re-opened, and about ten ounces of blood allowed to flow; and a turpentine enema was also administered, which produced a copious motion, similar in character to the former. These measures were adopted about 7 P.M. ; and, an hour afterwards, a starch enema, containing a drachm and a half of the Edinburgh College solution of the muriate of morphia, ${ }^{1}$ was administered. At 9 P.M., there was a little dilatation of the os uteri; she was quite calm : and when I examined the abdomen with the stethoscope, there was not the slightest muscular spasm. I could not detect the sounds of the fotal heart, and from the patient's statements, along with this negative evidence, I announced my belief that the fotus was probably dead, and that any operative interference, which might be required for the mother's safety, ought not be objected to, from the hope of a living child being ultimately born. Between 9 and 10, when I left her, she seemed disposed to sleep, breathed easily, and was perspiring. I gave instructions to the atterdants to administer the mixture formerly prescribed; and to send for me, if the convulsions returned, or if labour seemed to be advancing. To my surprise, I was not sent for during the night. It may here be stated, that hardly any urine was passed by the patient, during the twelve hours that I was in pretty close attendance upon her; and it was averred by her, that she had not made any for many hours before her seizure. For some days before that time, it was more abundant than natural. As to these facts, however, there was some ambiguity in the evidence. The important point, as regards the urine, is this-that what she passed (about two ounces) when I was with her, was found intensely albuminous, when treated by heat and nitric acid. The blood, especially that taken at the first bleeding, was cupped and buffed.

6th August. At 7 A.M., I found her in a quiet sleep : and was told that she had passed a tranquil night. Two doses of the antispasmodic mixture had been taken. The pulse was 74 ; and the skin moist. In the evening, she continued as well as in the morning. During the day, she took some beef-tea, and one or two doses of the mixture. There were some slight pains during my second visit, and an examination was then made, by which it was discovered that the os uteri was a little more dilated.

7th August. During this day, she continued in a comfortable and tranquil state, and sat up for some hours in the evening. When questioned as to her feelings, she said that she had some headache, and occasional pain in the back and abdomen. The os uteri was sufficiently dilated to admit the point of the fore finger. There was no preter-

1 The following is the formula for this preparation. Take of Muriate of Morphia, one drachm and a half; Rectified Spirit, fire fluid ounces; Distilled Water, fifteen fluid ounces. Mix the spirit and the water, and dissolve the muriate of morphia in the mixture with the aid of a gentle heat.

The uniformity of strength makes it preferable to the Tincture of Opium, when large dosea are given, and may have to be repeated. The London Pharmacopoia contains no officinal formula for prescribing the muriate or acetate of morphia, which is an inconvenient omission : but it gives instructions for preparing the salts, which are of no practical value to the physician or the pharmaceutist, and which the manufacturer would be sorry to take as his guides. 
natural heat of the part, and the digital examination caused no pain. No medicine was prescribed or taken. She had tro copious motions of an improved appearance. The urine was abundant, and was very slightly albuminous.

8th August. In the afternoon, when I called, the report of her state since my last visit was favourable. Her countenance was natural : but she complained of pain in the back, and also of headache. The urine was not chemically examined; it was sufficient in quantity : but the bowels had not again been moved. The breasts, which all along had been somewhat turgid, were now painfully so : they were hard, knotty, and painful to the touch, and a milky fluid exuded from them in such abundance, as to require frequent change of linen. A dose of sulphate of magnesia was prescribed; and an hour after it had been taken, a draught of henbane and valerian.

9th, 10th, and 11th, August. The urine was very slightly albuminous. During these days, the state of the mammæ was the only troublesome symptom. This was treated by gentle frictions, fomentations with poppies when the pain and tension were great, and by doses of sulphate of magnesia and tartar emetic, so as to keep up a watery discharge from the bowels. When she lay down, the headache returned, for which reason she was up and dressed the greater part of these three days. As she was up when I called, there was no digital examination made.

12th August. During the night (between the 11th and 12th) she had some slight convulsive attacks, and during the day, several of great severity. Her condition was so alarming, that I could not leave her even for a short time without anxiety; and during my short necessary absences, my assistant remained with her. She had convulsive attacks with the same periodic regularity, as the pains in ordinary labour; and though she was generally insensible, it was evident that with each fit the uterus was becoming dilated, and was actively engaged in the process of expul. sion. Though considerable progress was being made, yet from the great remaining rigidity of the os uteri, and the apoplectic aspect of the patient during the convulsions, I repeated the bleeding to the extent of about six ounces; and resolved, whenever the os uteri became a little more dilated, to perforate the head and extract the foetus. After the bleeding, however, the dilatation proceeded rapidly, and the convulsions greatly moderated : and though anxiously watching, I did not farther interfere. At 6 P.M., a dead foetus was born, without her having had, from the very first, what could be called labour pains; for her state throughout was generally one of insensibility, and the expulsive process went on steadily during each fit of Convulsions, which recurred in as regular paroxysms as ordinary labour pains. She made a complete and rapid recovery. Within a week, she was going about as if nothing had occurred to her. Her feelings of comfort were such, that all my cautions were thrown away; fortunately, no bad consequences resulted from the little care which she took of herself. I discontinued my attendance about the end of August.

Very soon afterwards, she became pregnant; and, in consequence, was much harassed with headache, nausea, and vomiting. I did not, however, see her again professionally, till the 21 st of January 1849, when I was, as on the first occasion, hurriedly sent for. I was told that she 
had just come out of a severe convulsive attack, similar to those from which she had formerly suffered. I found her not convulsed, but in a state of stupor, from which, however, she emerged speedily, though she continued in a somewhat stupid and bewildered state. The os uteri was soft, and dilated to nearly the size of a shilling. From this state of the womb, the regular recurrence of labour pains, (or rather of uterine contraction accompanied by convulsions,) and the absence of the alarming apoplectic symptoms which had characterized the convulsions which occurred in her first pregnancy, I thought that abortion would occur sufficiently soon to put the patient out of danger, and obviate the necessity for active treatment. After sufficient purging, anodynes were freely given. My prognosis, as to the speedy occurrence of abortion, proved erroneous; for the uterine contractions and the Convulsions both subsided within twelve hours, the patient got quite well, went about with her dilated uterus, and did not miscarry for two months. Abortion took place on the 23rd of March. From the 22nd of January to the 20th of March, she enjoyed tolerable health, and had no recurrence of the convulsions. When she allowed a day to elapse without going to stool, she suffered from headache and giddiness, but a little care in regulating the bowels obviated these unpleasant symptoms. On the 20th, labour pains set in, and continued, with longer or shorter remissions, till a dead foetus, of apparently between the 6th and 7th month, was expelled on the 23rd of March, without much suffering, and without the recurrence of convulsions. After the abortion, she made a speedy and complete recovery ; and has since enjoyed good health.

Remarks. The observations which follow, though suggested by the preceding cases, apply, in a great measure, to the subject of Puerperal Convulsions generally. It has long been familiarly known to practical obstetricians, that convulsions are to be dreaded in women who have become œdematous during pregnancy; but till very lately the meaning of the sign was not attended to, and even yet has not been fully appreciated. In a work on Obstetrics, published in America during the present year, Dr. Meigs, in speaking of adema gravidarum, says :- "It is proper to remark, that women, who are very much swelled, are to be deemed far more liable to Puerperal Convulsions, than such as have no swellings; for these infiltrations, produced by pressure on the ascending venous columns, suffer a similar pressure under the descending arterial columns of blood ; which gives cephalic engorgement. Good care should be taken to obviate such dreadful attacks. To be forewarned, is to be forearmed."' It would be strictly correct to go farther than Dr. Meigs, and to say, that Puerperal Convulsions very rarely occur in women who are not œdematous to a greater or less extent. It would likewise be true to say, that, along with the dropsy, there exists an albuminous condition of the urine. Many women have slight œdema and albuminuria, and some have both to a considerable extent, and yet escape convulsions; but, if we exclude hysterical convulsions, and convulsions from anæmic affections, which are not peculiar to the puerperal state, very few, if any, of those affected with true eclampsia gravidarum, are

1 Mrigs (Dr. Charles D.), Obstetrics; the Science and the Art, p. 206. Pliladelphia : 1849. 
not the subjects of anasarcous effusion and albuminuria. Attention was, I think, first directed to the coincidence of albuminuria with Puerperal Convulsions by Dr. John Lever. He announced the fact, that in nine out of ten cases, in which he had examined the urine, it was found to be albuminous. ${ }^{1}$ Drs. Devilliers and Regnault, in a valuable memoir on the Dropsy of Pregnant Women (published during the past and present years in the Archives Générales de Médecine), declare, as a remarkable and essential fact, that "chez toutes les femmes éclamptiques, on trouve de l'albumine dans les urines. Cette régle ne nous a pas encore paru souffrir d'exceptions." If it be a fact, then, that albuminous urine and anasarca- the characteristic signs of congested kidneybe so common in Puerperal Convulsions, as to be regarded, by the best and most recent authorities, as their constant concomitants, it may, I think, be very safely inferred, that the renal congestion is the cause of the convulsions; or, to be more explicative and precise-that the convulsions are direct toxicological effects on the nervous centres, produced by poisonous substances which the unembarrassed kidney could throw off with the urine, but which the congested kidney cannot excrete. In pregnant women, blood-poisoning exists far more commonly than is generally believed. There is a series of phenomena resulting from different degrees of toxæmia-such as nausea, vomiting, coma, delirium, convulsions, and mania-which may, on a subsequent vccasion, form, either separately or collectively, the subject of another paper.

It is important to remember, that the gravid uterus, or other tumour, pressing on the renal veins, or in any way seriously impeding the return of blood from the kidneys, must induce, more or less, inability on their part to perform their emunctory office ; and, when the pressure is great, a consequent condition of toxæmia. It must also be remembered, that the maternal blood, during utero-gestation, notwithstanding the demands made on it for phosphate of lime, etc., by the fotus, requires, in some respects, an extra degree of depuration, and that, therefore, the pregnant woman can very ill bear an impediment to the free return of blood from the kidney. She probably requires, for her preservation in health, to throw out a large additional amount of excrementitious matter from her blood, as it is charged with the matter depurating from the fœtus, in addition to the ordinary depuration essential to her maintenance in health in the non-pregnant state. The elements of the milk also require, during utero-gestation, to be thrown off by the kidneys; and " kiestein," which may generally be found in the urine after the second month of pregnancy, is presumptive evidence that this depuration is going on ; for Dr. Golding Bird, Dr. Peddie, and others, have shown that this product contains some of the elements of the milk. ${ }^{3}$ Dr. Golding Bird says :- " the imperfectly formed secretion of milk, not

I Lever (Dr. John), in Guy's Hosp. Rep., Second Series, p. 495. London : October 1843.

- Devillers et Regault, Archives Gén. de Médecine, 4mo Serie, t. xvii, p. 205. Paris: Juin, 1848.

- Prdpre (Dr. Alexander), on the Mammary Secretion, in Edinburgh Monthly Journal of Med. Science, Aug. 1848. He says :- "With the aid of the microscope, I have fully satisfied myself that this prodnct (kiestein) contains some of the elements of the milk." This observation of Dr. Peddie may be doubted by some, becanse kiestein has been found in the urine of non-pregnant women, aud even in the urine of men. Its presence indicates that a species of depuration is going on, but with the nature of it, we are not yet fully acquainted. 
having a ready exit by the mammm, is taken up into the circulating mass, is separated by the kidneys, and eventually escapes from the body by the urine."1 Many of the distressing symptoms, which so often attend pregnancy ought, I think, to be considered as resulting from toxæmia, dependent on defective sanguineous depuration, and treated accordingly. I must not be understood as saying that diminished renal elimination is the only cause. The skin, the lungs, the liver, or the kidneys, may one or all be in fault : but, from the pressure of the gravid uterus, the latter run the greatest risk of having their functions impaired. If the kidneys be embarrassed from the congestion caused by the gravid uterus, urea will remain in the blood, and likewise the elements of the milk. The non-elimination of the lacteal elements is much less dangerous than the retention of carbonic acid in the lungs, or of the poisonous principles of the bile and urine ; as the former, being oleaginous, saccharine, and albuminous, are not very dissimilar to the constituents of the blood. Milk fever, however, which ought to be regarded as truly a poison-disease, is sometimes pretty severe, if active derivative treatment be not adopted. The state of the mammæ in the case of Mrs. H. merits special notice. In her, most probably, the elements of the milk were not adequately got rid of by the kidneys.

The Convulsions occurring to virgins and others at the menstrual period, commonly known by the name of Uterine Epilepsy, are often reflex phenomena, but they may in many cases depend on toxæmia sometimes acting as a predisposing, and at other times as a centric and direct, cause : for the poisonous nature of menstrual blood, and its highly carbonized constitution, is believed in by physicians and chemists.

The same remarks apply much more strongly to the lochial discharge. Its suppression, like that of the menses, may induce attacks of Uterine Epilepsy, or, to use the other name, Puerperal Convulsions. In such cases of post-partum Puerperal Convulsions, should no structural disease of the kidney exist, the urine is not likely to be albuminous, nor the surface odematous: but I am inclined to think, from cases which have occurred under my own observation, that anasarca is present in a large proportion of those cases in which convulsions occur from suppressed menses. 2 In such circumstances, I have seen anasarca, albuminous urine, and lethargy, which were soon relieved by purging: more serious results being probably averted by this treatment. There must have existed renal congestion.

It generally happens that when the uterus is emptied, the convulsions cease : and they seldom recur after delivery. When they do recur, we must suspect an insufficiency in the lochial secretion, or structural renal disease. The explanation of delivery generally arresting the Convulsions, is not so much that the uterine irritation is lessened, as that the kidneys are relieved from their hyperæmic condition, and thus become enabled to resume the proper exercise of their function.

By adopting this view, we obtain an EXPIANATION OF THE MUCH GREATER FREQUENCY OF PUERPERAL CONVULSIONS IN PRIMIPARE.

1 Brad (Dr. Golding), in Guy's Hospital Reports, April 1840.

I hare published cases of Convulsions and Mania from suppression of the catamenia, in an Essay on Transient Insanity, in the Edinburgh Mouthly Journal of Medical Science, p. 903 , vul. for 1813 . The cases in that paper might bave been correctly considered as illustrations of toxamia. 
The individuals most commonly the subjects of Puerperal Convulsions are strong healthy young women, pregnant for the first time : that is to say, a class of patients in whom the abdominal walls aro the most unyielding, and least able to relax under the pressure of the expanding womb. Dr. Collins says that "Puerperal Convulsions occur almost invariably in strong plethoric young women with their first children, more especially in such as are of a coarse thick make, with short thick necks"; and "in thirty cases which occurred during his mastership, twenty-nine were in women with their first children; and the other single case was a second pregnancy, but in a woman who had suffered a similar attack with her first child." Some of the particulars of this case are detailed by Dr. Collins. Convulsions occurred after as well as during labour, which leads us to suppose that the toxæmia did not depend mainly, or at least not entirely, on renal causes. The patient may, however, have been the subject of such structural renal disease as to facilitate the production of dangerous congestion, or she may have had some ovarian or other tumour causing like tendencies. The uterine excitement may also undoubtedly, in some cases, be the immediate cause of exciting Convulsions in those in whom toxæmia pre-existed, though remaining latent as to its effects, being only of sufficient intensity to operate as a predisposing cause. Dr. Joseph Clarke mentions nineteen cases of Puerperal Convulsions, of which number sixteen occurred in primiparæ. ${ }^{2}$ Dr. S. Merriman met with forty-eight cases, and thirty of them were in primiparæ. ${ }^{3}$ Dr. Lever, in his paper already referred to, notices that eight out of his fourteen cases were in first pregnancies. It would be interesting to know how many of the eight had ever gone to the full time, as well as other particulars with which we are not furnished. Chailly observed thirteen cases at La Clinique of Paris, of whom nine were in primiparæ: Dr. Johns, quoting from the ward-book of the Dublin Lying-in Hospital for a period of two years, mentions that of nine women who had convulsions, and twelve who were threatened with them, all except two were pregnant for the first time. These two had had convulsions in previous labours. It is to be regretted that many of the most esteemed authors, in giving their experience in this class of cases, do not state how many occurred in first births: but the above accounts being taken without selection from such works as I have access to, may be considered as probably a fair view of this question in obstetric statistics. It is not perhaps necessary to multiply citations of this kind, as the fact of primiparous women being the most subject to Convulsions is generally recognized : but I may just add, that I am now, as leisure admits, engaged in an analysis of all the reported cases of Puerperal Convulsions, and find that as the number of cases augments, so, in like proportion, is the augmentation in those which were first pregnancies. At present the following tabular recapitulation may suffice :

1 Colnsss (Dr. Robert). Practical Treatise on Midwifery, containing the result of 16,664 births which occurred in the Dublin Lying.in Hospital, p. 201. Iondon: 1834.

- Collons. Op. cit. p. 200.

Merriman (Dr. Samurl). Synopsia of the Various Kinds of Difficult Parturition. New Fdition, p. 148. London : 1838. 
BY JOHN ROSE CORMACK, M.D., F.R.8.L.'

\begin{tabular}{|c|c|c|c|c|}
\hline $\begin{array}{l}\text { By whom } \\
\text { observed. }\end{array}$ & $\begin{array}{c}\text { First } \\
\text { Pregmancies }\end{array}$ & $\begin{array}{l}\text { Bubsequent } \\
\text { Pregnancies }\end{array}$ & $\begin{array}{l}\text { Total } \\
\text { cases. }\end{array}$ & Whence quoted. \\
\hline 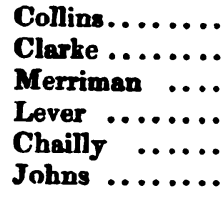 & $\begin{array}{r}29 \\
16 \\
86 \\
8 \\
9 \\
19\end{array}$ & $\begin{array}{r}1 \\
3 \\
12 \\
6 \\
4 \\
2\end{array}$ & $\begin{array}{l}30 \\
19 \\
48 \\
14 \\
13 \\
21\end{array}$ & $\begin{array}{l}\text { Coilins, op. cit. p. } 201 . \\
\text { Collins, op. cit. p. } 200 . \\
\text { Merriman, op. cit. p. } 148 . \\
\text { Guy's Hosp. Rep. } 1843 . \\
\text { Chaily, by Bedford, p. } 265 \text {. } \\
\text { Dub. Journal, Sept. } 1843 .\end{array}$ \\
\hline Total. . & 117 & 28 & 146 & \\
\hline
\end{tabular}

In primiparous women there is-as a general rule-a greater tenseness and rigidity of the abdominal parietes; and therefore in them the gravid uterus is much more apt, by its inward pressure, to cause dangerous renal congestion. This obviously explains why primipara are the most liable to Puerperal Convulsions; and why Convulsions in them are chiefly of a renal, and therefore of a severe and epileptoid character. It is probable that in them albuminuria is associated with the cedema of the face and upper part of the lody, which is sometimes seen in many of them who escape Convulsions : for it must be remembered that the albuminuria and cedema are simply signs of congested kidney, and that congestion may exist-and indeed often does exist-to an extent quite sufficient to cause these phenomena, and yet be inadequate to produce toxæmia of sufficient intensity to cause Convulsions.

The frequent omission of details renders it impossible to make a complete analysis of the history of those cases in which convulsions occurred in subsequent pregnancies: but the result of my inquiry is, that all the fully reported cases which in their mere numerical aspect limit the rule, on a scrutiny tend to establish it. These cases may be considered as chiefly toxæmic, but some are non-toxæmic. Those of toxæmic origin may all be classed under four heads, viz.: 1. Persons who, though previously pregnant, had never gone to the full time, and in whom, therefore, there had been no relaxing of the abdominal walls. 2. Persons of extreme muscular development, whose rigid fibres do not readily yield to the augmenting womb. 3. Persons who, from organic changes in the structures of the kidney, cannot adequately perform reual depuration of the blood; among whom may be included-those suffering from granular or other structural disease of the kidneys; or who have some congenital anatomical peculiarity in these organs; ${ }^{1}$ or in whom some morbid growth presses on the emulgent veins, or, indirectly by its presence, impedes the free flow of blood through these vessels. 4. Excessive volume of uterine tumour, including plural pregnancies, and cases of superabundant liquor amnii.

1 This remark brings to my recollection a remarkable case, of which the following brief ontline is given by Dr. Robrat Lre, at p. 112 of his Clinical Midwifery. "A young woman, in the sixth month of her second pregmancy, died of chorea, on the 29th Angnst 1840, in St. George's Hospital. The symptoms were at first slight, and were apparently produced by fright. The convulsive movements became so violent, that it was found necessary to put on a strait-waistcoat, and fix her down to the bed. Forty-seren bours before death, the contents of the uterus were expelled. The brain and spinal marrow were perfectly healthy. There were some small vegetations in the mitral valves; the right kidney and ureter were wanting; the supra renal capsale was present. The uterus was in a natural state. The corpus lutenm was unusually small, and the coats of the Graafian vesicle conld scarcely be seen within the Jellow matter." 
The first class is very numerous; and embraces the second attack of my patient, Mrs. $H$.

The secund class seems also to include a number of cases.

The third class is not numerous . but it is important, when we recollect how often, in the course of Bright's disease, when we have greatly relieved the head symptoms, and reduced the oedema and albuminuria by derivative treatment, Convulsions or death abruptly occur from exposure to cold, from some error in diet, or other accidental cause. In such instances the coagulability of the urine returns to its greater degree of intensity. It is quite plain that a pregnant woman labouring under Bright's disease, even in an early stage, must in this way run a tenfold risk of Convulsions. If she have an ovarian tumour, or any other mechanical predisposing cause to renal congestion besides the gravid uterus, her risks will also be great. In her, too, delivery will hardly bring exemption from the danger of toxæmia from renal non-elimination. Dr. Simpson said, in 1843,1 that he had been accustomed to teach in his Lectures, that " patients attacked with Puerperal Convulsions had almost invariably albuminous urine, and some accompanying or rather preceding dropsical complications, and hence probably granular renal disease." This latter remark of Dr. Simpson, with deference to so high an authority, I must dissent from. Under proper management, the majority of those affected with Puerperal Convulsions quickly and perfectly recover, and in future pregnancies are very rarely affected. Undoubtedly, women who have structural disease of the kidneys are preeminently liable to renal congestion and consequent toxæmia : but then œdema, albuminuria, and Convulsions, are not in the Puerperal woman pathognomonic of any organic disease of the kidney, though in the fatal cases we may expect them to be often present. Dr. Simpson's cases, to which I formerly referred, are interesting in this point of view. In three fatal cases of Puerperal Convulsions, he found on dissection a great amount of renal-disorganization. Albumen was looked for in the urine during life, but was not found.2

The fourth class of cases is interesting. More accurate statistics, than those yet given by authors, are required, before we can do more than state generally that a bulky uterine tumour predisposes to Convulsions : and that in some its presence may render a subsequent pregnancy as liable to them and in the same way, as the rigid parietes of a primiparæ. The facts which best illustrate this position, are such as the following :-Dr. Collins, in 240 cases of twins, had three cases of Convulsions : and in his grand total of 16,654 labours, he had only thirty cases of Convulsions ; hence, in twin cases there occurred 1.25 per cent., and in single pregnancies 0.18 only per cent. Two of Dr. Merriman's 48 cases of Puerperal Convulsions were twin cases; and so were two of the 13 cases reported by Chailly. It is to be regretted, that Drs. Merriman and Chailly do not give the total number of labours, in which these cases occurred. With regard to some of the Convulsions which occur after delivery, it must be borne in mind, that they are not toxæmic, but truly

\footnotetext{
1 Edinburgh Monthly Journal, Nov. 1843, p. 1015.

- LoNdon JovRe al or MEDicine for last month, p. 453: and Edinburgh Monthly Joumal for September 1817, p. 212.
} 
anæmic; and in some of the twin cases in which there was much hæmorrhage, want of blood seems to have been the cause of spasm.

Some authors have explained the fact of the unmarried being more subject than the married to Puerperal Convulsions, by assuming, that in the former, greater emotional causes are present. Another explanation, however, is more in accordance with the series of facts now brought forward. Allowing that emotion may often, both in the married and unmarried, be concerned as an accessory cause; and granting that it may even sometimes be the proximate cause of exciting Convulsions, through the medium of a brain ${ }^{1}$ already in an apt state to be so influenced, in consequence of the action of previous toxæmia; yet, as regards those who have become pregnant out of wedlock, it seems natural to infer, that the tight girding of the abdomen, which they so often practise to such an extraordinary extent, to conceal their shame, may act most powerfully, in producing extreme congestion of the kidney and consequent intense toxæmia.

Death of the foetus in Mrs. H. seemed, in both pregnancies, to precede the attacks of Convulsions. This observation is important, because when this event takes place, there is inevitable toxæmia, which may be looked on as nature administering a poison for the purpose of accomplishing abortion. If the fotus die, the matters which were being taken out of the mother's blood for its growth, suddenly cease to be required : and the depuration by the foetus also ceases. ${ }^{2}$ In these circumstances there must, I think, be more or less toxæmia. When the supply of material for the fotus from the uterine vessels of the mother suddenly terminates, by its birth at the full time, the lochial discharge comes to her relief, and so long as it is in sufficient abundance, she has small hazard of toxæmia. That to preserve from toxæmia is the use of the lochial discharge cannot be doubted, when we contemplate the phenomena which arise when it is scanty or suppressed; and when we see that in most instances in which women who do not nurse their infants and yet enjoy good health, it continues to flow for six weeks in place of ten or fourteen days. When Convulsions occur or recur after delivery, the toxæmia most probably arises from imperfect excretion or complete suppression of the lochia: but it may also depend on the kidney being congested from structural disease in itself, or from pressure on the veins caused by the morbid enlargement of some neighbouring part.

It must be borne in mind, that though the puerperal woman is liable to Convulsions from special causes, she is also subject to them from others which act on persons who are not gravid; though from some convulsive attacks, e.g. epilepsy, she seems very frequently to be respited, in virtue of her pregnancy. The following arrangement of Convulsive affections, with reference to their causes, as they occur both in the Puerperal and Non-puerperal states, seems to be correct and convenient.

1 The brain, properly so called, can, we suppose, have, in any circumstances, but an indirect share in causing conrulsions, which depend on the spinal column and medulla oblongata. The acephalous fotus generally dies of convulsions.

2 The meconium with which the bowels are distended at birth, and the urine found in the bladder, are clear proofs of active fotal depuration. If the fotus performed no bloodmoulcing for itself, it would not contain within it deposits of excrement, nor would it be so liable to diseases similar to those of extra-nterine life. 
1. Toxsmin,

2. ANamia,

8. HYPeremia, Or

4. IREITATION OP THE EXTREMITIBS OF THE NBETEs,
AIL CONVULSIONS ARIST FRON

$\left\{\begin{array}{l}\text { ecting directly on the spinal column and modulla } \\ \text { oblongata. }\end{array}\right.$

Sacting in a reflex manner on the spinal column and $\{$ medulla oblongata.

The sources of toxæmia causing convulsions are very various. They may be thus succinctly arranged.

SOURCES OF TOXEMIA CAUSATG CONVULSIONS.

I.

Depective Deporation OP THE BLOOD.

(1. Non-erolution of carbonic acid, etc. by the lungo.

2. Non-limination of the principles of the bile from the blood.

3. Non-limination of the principles of the urine from the blood.

4. Non-elimination of urea, etc. by the skin. 1

5. Non-elimination of accidental efiete matters from the blood, by the kidneys and other emunctories.

II. (1. Inorganic poisons, such as acetate of lead, etc.

Intzodoction of Foreign $\{$ 8. Organic poisons, such as strychnia, etc.

MatTza into res Brood. (3. Morbid poisons, such as scarlatina, etc.

While the pregnant woman is not exempt from any of the above causes of toxæmia, she is specially in danger from those comprised under the third and fifth divisions of the first head: viz. non-elimination of the principles of the urine by the kidney; and non-elimination of accidental effete matters from the blood by the kidneys and other emunctories. While admitting the importance of every emunctory to the puerperal woman, it may still be correctly stated, that all

\section{Toxamic Puerperal Convolsions are mainly}

\section{RBNAL, OT \\ 2. Lochial:}

or they may partake of both, along with other, characters. The chief object of the present paper is to point out the importance of the former : but in doing so, I wish explicitly to mention defective elimination from any organ as a cause of more or less toxæmia : and also to recognize non-toxæmic causes of Puerperal Convulsions.

1. Renal. Puerperal Convulsions. The following diagram shows how pregnancy of itself may cause Renal Convulsions:

\section{PREGNANCY}

CAU8B8

Increased necessity for Renal Depuration of Blood.
A tumour (gravid uterus) causing renal congestion, which

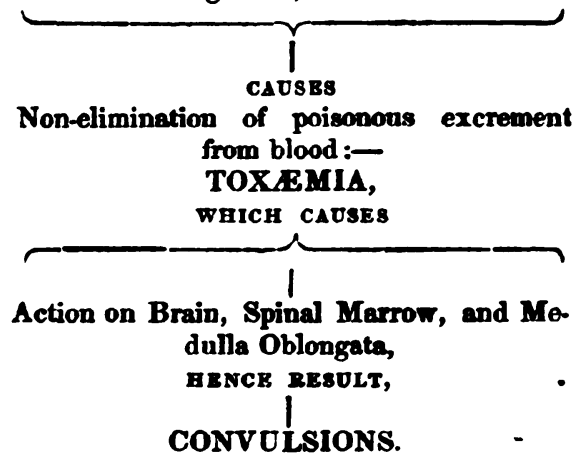

1 Landerer has shewn that urea is normally excreted by the alin. (Dr. Garrod's Lectures in Lareet, vol. ii, 1848, p. 653.) It is rery important to beer this in mind, for it shows that 
The existence of organic disease of the kidney greatly augments the risk of Renal Convulsions during the Puerperal state. And as was formerly stated, the continuance of the pressure of the gravid uterus after the death of the foetus, must be specially apt to induce toxæmia; for if the elements for the nutrition of the fœetus suddenly cease to be required, the maternal blood must for a time be charged with superfluous and foreign matter.

The Prophylaxis of Renal Puerperal Convulsions must evidently embrace an avoidance of too long continuance in the supine position; an easy corset, giving free play to the lungs, and not pressing back the womb; moderate exercise; regularity and sufficiency of the alvine evacuations, and a good state of the skin. Mental excitement must also be avoided, as it might, even with a moderately poisoned state of the blood, be the immediate cause of Convulsions. It is natural to suppose, that when toxæmia is present, congestion of the nervous centres is more dangerous than when the superabundant blood is healthy.

The Treatment of Renal Puerperal Convulsions is a subject on which a great deal might be said; but having already exceeded my limits, the leading intentions only, are, for the present, indicated in the following diagram :

TREATMENT.

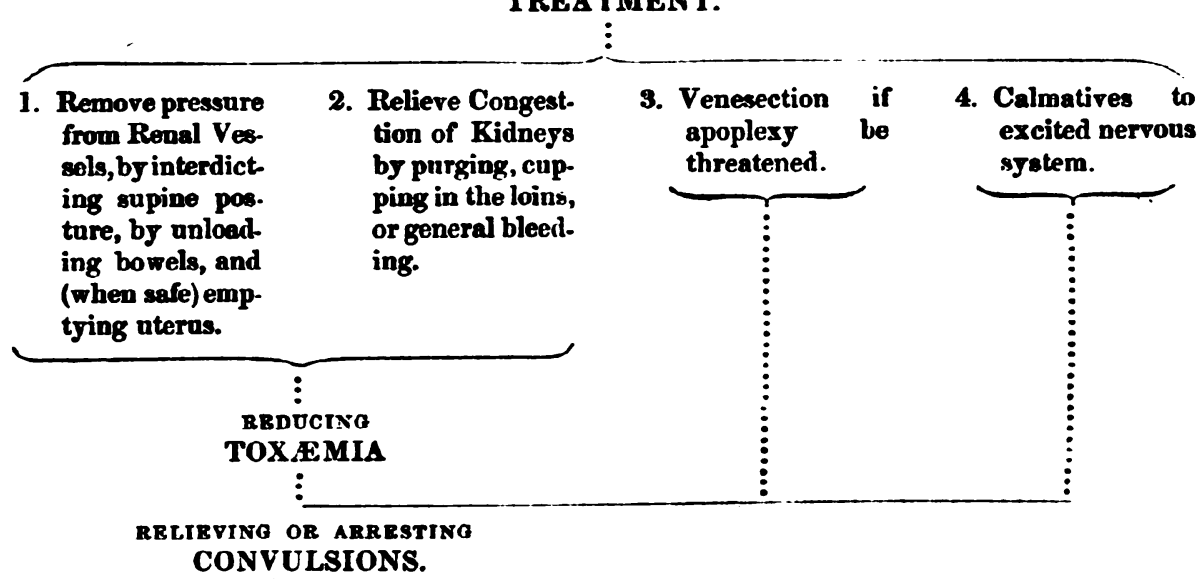

A few remarks on Lochial Puerperal Convulsions, along with some observations on Non-Toxæmic Puerperal Courulsions, are deferred to a future occasion.

Essex House, Putney, Muy 1819.

an increased action of the skin may relieve the kidneys in other ways than merely by getting rid of water. In the report of the case of H. L. D. (Scarlutinous Ney,hritix), at p. 456 of the last Number, it is noted, that at one period there was retention of urine for seventy hours, during which the patient had a strong urinous smell. The skin was in this instance acting vicariously for the kidney; and by the breath also, most probably, were exhaled the poisonons constituents of urine. 